\title{
SCREEN-PRINTED ELECTRODES MADE ON STONE PAPER SUBSTRATE FOR URIC ACID ELECTROCHEMICAL DETECTION
}

\author{
CODRUTA VARODI ${ }^{a}$, FLORINA POGACEAN ${ }^{a}$, MARIN GHEORGHE ${ }^{b}$, \\ LUCIAN BARBU-TUDORAN ${ }^{a}$ and STELA PRUNEANUa,
}

\begin{abstract}
Flexible screen-printed electrodes on stone paper substrate (HP) and modified with gold nanoparticles (HP-AuNPs) or AuNPs-poly-methylene blue (HP-AuNPs-PMB) were fabricated and morphologically investigated by SEM/EDS. The electrochemical properties of the new electrodes were studied by cyclic voltammetry (CV). The best electrocatalytic properties for uric acid detection were obtained with HP-AuNPs electrode: $0.16 \mu \mathrm{M}$ Limit of Detection, $5 \times 10^{-7}-10^{-4} \mathrm{M}$ linear range and $20.7 \mathrm{~mA} / \mathrm{M}$ sensitivity.
\end{abstract}

Keywords: uric acid detection, stone paper substrate, AuNPs modified electrodes

\section{INTRODUCTION}

Uric acid is a waste product created during the metabolism of proteins. It is normally cleaned out of the blood by the kidneys, and passes out of the body along with urine. The high concentration of uric acid in the blood will eventually convert the acid into urate crystals, which can then accumulate inside the body leading to various diseases like gout, LeschNyhan syndrome, urolithiasis, kidney damage, leukemia, lymphoma [1]. The detection of UA in human body has considerable importance for clinical analysis and diagnosis.

\footnotetext{
a National Institute for Research and Development of Isotopic and Molecular Technologies, Donat Street, No. 67-103, RO, 400293, Cluj-Napoca, Romania

b NANOM MEMS srl, G. Cosbuc Street, No. 9, RO, 505400, Rasnov, Brasov, Romania

*Corresponding author: stela.pruneanu@itim-cj.ro
} 
Various methods for the determination of UA have been reported, such as chemiluminescence [2], fluorimetry [3], spectrophotometry [4], enzyme assay [5], chromatography [6-8], electrophoresis titration [9], gamma radiolysis [10] and electrochemical methods [11-15].

The interest for the development of a new generation of biodegradable electronics [16-17] made by non-toxic materials and for renewable and wastebased materials as substrates for electrochemical electrodes is highly increasing in the last decades. The electrodes based on textile, hydro chars waste, carbon rod from zinc-carbon batteries, CD/DVD, ITO from photovoltaic device, PVC, ceramic, paper or other types of materials re-designed in a greener approach the analytical electrochemistry [18].

In this context, stone paper is very attractive for flexible device applications. It is a composite material made of calcium carbonate and a nontoxic resin, high-density polyethylene (HDPE). It is not biodegradable but is photo-degradable under suitable conditions [19]. The production of paper from stone offers significant environmental benefits such as no major deforestation.

In this research, we used stone paper as substrate for developing new modified electrodes, with excellent electrocatalytic activity for the oxidation of uric acid.

\section{RESULTS AND DISCUSSION}

The flexible screen-printed electrodes on stone paper substrate (HP) can be connected to a laboratory potentiostat. Two HP electrodes were modified either with gold nanoparticles (HP-AuNPs) or gold nanoparticles and polymethylene blue (HP-AuNPs-PMB) and were morphologically characterized before the electrochemical testing for uric acid detection.

\section{Morphological characterization of the flexible screen-printed electrodes (HP, HP-AuNPs and HP-AuNPs-PMB)}

SEM technique coupled with EDS analysis was used for the morphological characterization of the new flexible screen-printed electrodes (HP and HP-AuNPs).

The image of bare HP electrode (Figure 1a) reveals a porous surface with graphite particles have irregular shapes and the size in the range of hundred of $\mathrm{nm}$. After AuNPs electrodeposition, round particles attached to the electrode surface can be observed. The changed morphology of modified electrode is presented in Figure 1b. The effect of poly-methylene blue was to cover the electrode surface, including the gold nanoparticles as can be seen in Figure 1c. 

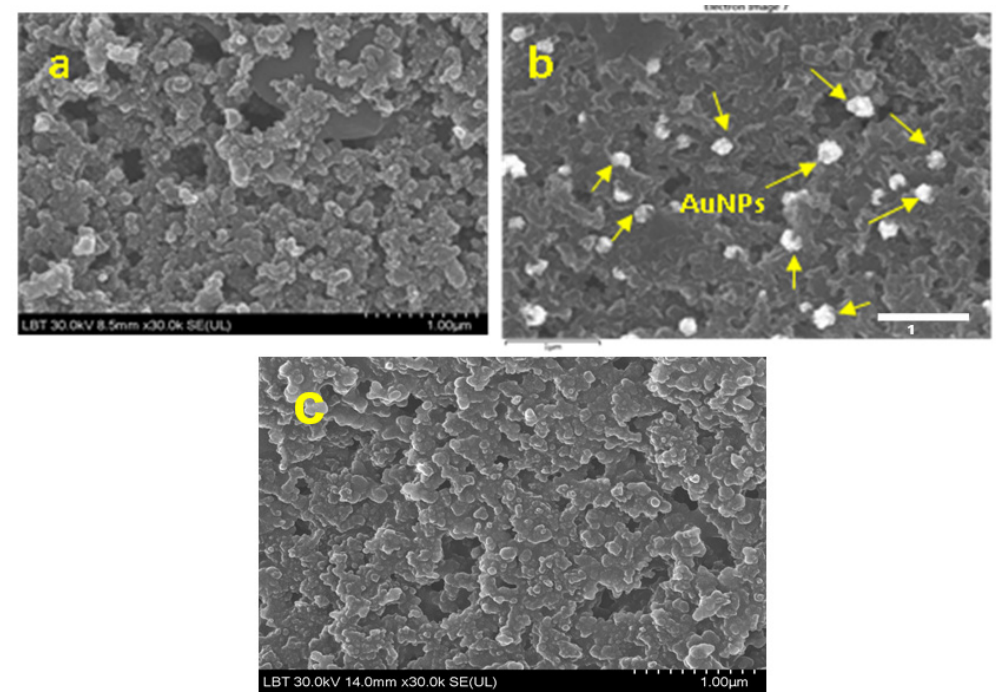

Figure 1. SEM image of HP electrode (a), AuNPs modified electrode (HP-AuNPs) (b) and PMB-AuNPs modified electrode (HP-AuNPs-PMB) (c); scale bar: $1 \mu \mathrm{m}$.

The EDS analysis (Figure 2) confirmed that the paper surface printed with carbon ink has carbon in its composition (yelow) and the nanoparticles from the modified electrode surface were gold (red).
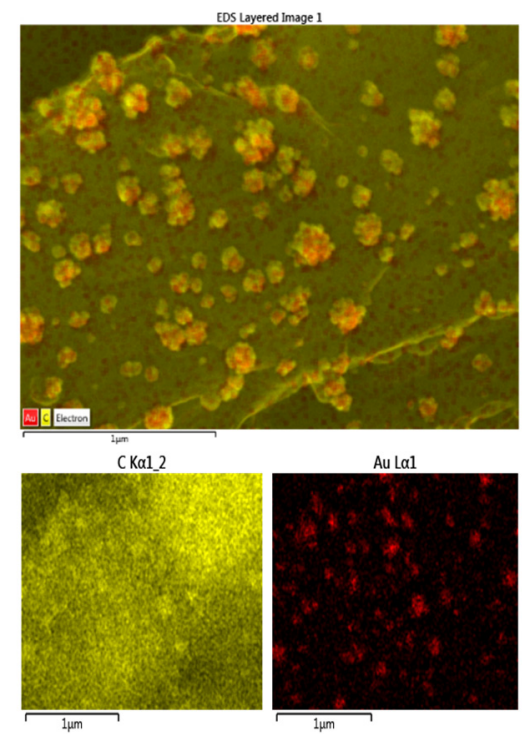

Figure 2. EDS analysis of HP-AuNPs electrode, confirming the presence of carbon (yellow) and gold (red) elements within its surface; scale bar: $1 \mu \mathrm{m}$ 


\section{Electrochemical active areas of the flexible screen-printed electrodes}

The new flexible screen-printed electrodes were electrochemically characterized by cyclic voltammetry in a redox couple solution $(1 \mathrm{mM}$ $\mathrm{K}_{4}\left[\mathrm{Fe}(\mathrm{CN})_{6}\right]+0.2 \mathrm{M} \mathrm{KCl}$ ), between $-0.2 \mathrm{~V}$ and $+0.65 \mathrm{~V}$ potential range. In this one-electron redox reaction (Scheme 1), the ferricyanide ion $\mathrm{Fe}(\mathrm{CN})_{6}{ }^{3-}$ is an oxidant and the ferrocyanide ion $\mathrm{Fe}(\mathrm{CN})_{6}{ }^{4-}$ is a reductant. This reversible redox couple is a standard in electrochemistry [20].

$$
\begin{array}{ccc}
\mathrm{Fe}(\mathrm{CN})_{6}{ }^{4-}-\mathrm{e}^{-} & \stackrel{\text { Oxidation }}{\stackrel{\text { Reduction }}{\leftrightarrows}} \mathrm{Fe}(\mathrm{CN})_{6}{ }^{3-} \\
\text { Ferrocyanide ion } & \text { Ferricyanide ion }
\end{array}
$$

Scheme 1. Potassium ferrocyanide/ferricyanide reversible one-electron redox reaction

Their active areas were calculated with Randles-Sevick equation, after recording cyclic voltammograms at different scanning rate $(2,5,10,15$, $\left.20,30,40,50,100 \mathrm{mVs}^{-1}\right)$. The linear plots obtained between the anodic peak current $\left(I_{p}\right)$ of each electrode and the square root of scan rate $\left(v^{1 / 2}\right)$ are presented in Figure 3.
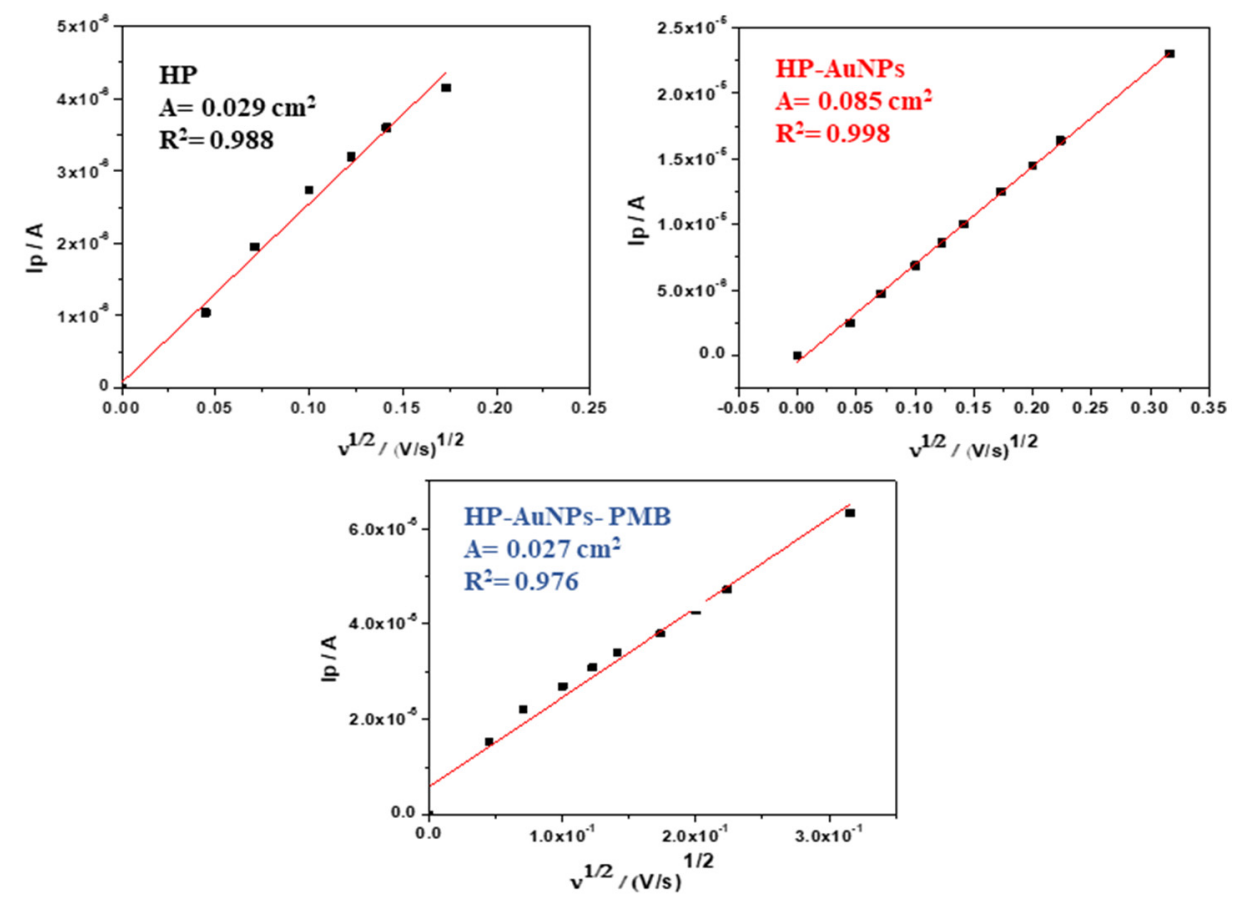

Figure 3. The linear plots obtained between anodic peak current $\left(I_{p}\right)$ and the square root of scan rate $\left(\mathrm{v}^{1 / 2}\right)$ with new flexible screen-printed electrodes in the presence of $1.0 \mathrm{mM} \mathrm{K}_{4}\left[\mathrm{Fe}(\mathrm{CN})_{6}\right]+0.2 \mathrm{M} \mathrm{KCl}$, at different scanning rates 
As can be seen in these figures, AuNPs had a benefic effect leading to a considerably increase of the active area of the modified electrode $(-3$ times, from $0.029 \mathrm{~cm}^{2}$ to $0.085 \mathrm{~cm}^{2}$ ). In contrast, the electrodeposition of PMB over the electrode modified with AuNPs had an opposite effect and the active area considerably decresed $\left(0.027 \mathrm{~cm}^{2}\right)$.

\section{Electrochemical detection of uric acid (UA) with HP, HP-AuNPs and HP- AuNPs-PMB flexible electrodes}

In order to investigate the analytical applicability of new flexible screenprinted electrodes HP, HP-AuNPs and HP-AuNPs-PMB, they were tested for uric acid detection. Cyclic voltammograms recorded with the electrodes in $\mathrm{pH}$ 6 PBS solution containing $0.1 \mathrm{mM}$ uric acid are shown in Figure 4. The signals generated by the three electrodes are different. In the case of bare HP electrode (blue), the oxidation wave is broad and small. The electrode modified with AuNPs-PMB gives a higher signal, but the best signal was that recorded with HP-AuNPs. In addition, the electrocatalytic effect of HP-AuNPs electrode was indicated by the clear shift of the peak potential, from 0.45 to $0.205 \mathrm{~V}$.

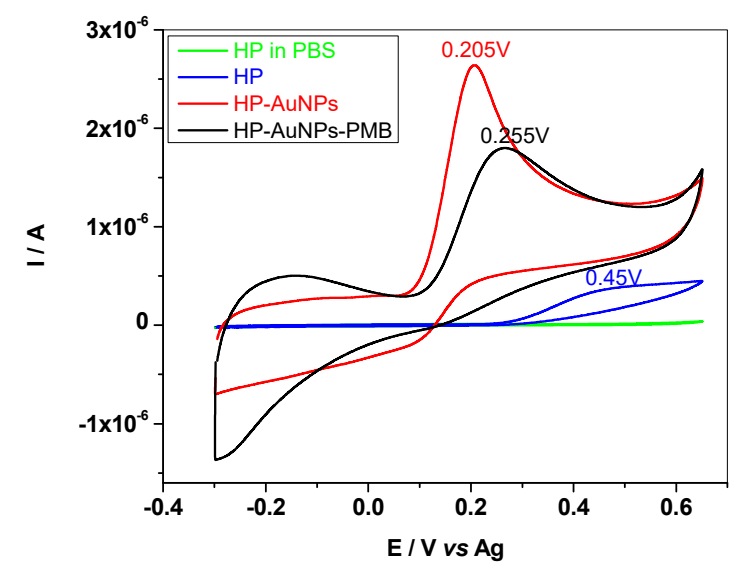

Figure 4. Cyclic voltammograms recorded with HP, HP-AuNPs and HP-AuNPsPMB flexible electrodes in the absence and presence of $0.1 \mathrm{mM}$ uric acid.

Supporting electrolyte: $\mathrm{pH} 6 \mathrm{PBS}$; scan rate $10 \mathrm{mVs}^{-1}$.

The bare and modified electrodes were next employed to record cyclic voltammograms in solutions containing various concentrations of uric acid $\left(10^{-7}-10^{-4} \mathrm{M}\right.$; pH6 PBS supporting electrolyte). For exemplification, in Figure $5 \mathrm{a}$ are shown the CVs recorded with HP-AuNPs. The superior performances of the HP-AuNPs modified electrode are further confirmed by the obtained calibration plot, Figure $5 \mathrm{~b}$. A higher sensitivity of the AuNPs modified electrode $(20.7 \mathrm{~mA} / \mathrm{M})$ in comparison with bare $(1.23 \mathrm{~mA} / \mathrm{M})$ or AuNPs-PMB electrode (11.7 mA/M) can be clearly observed. 

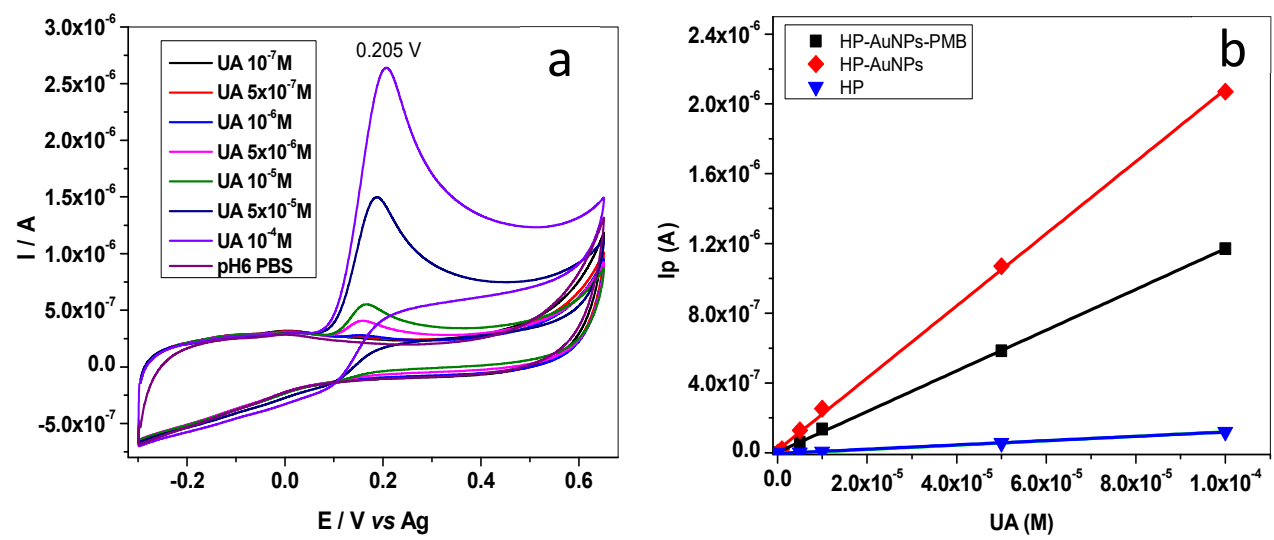

Figure 5. Cyclic voltammograms recorded with HP-AuNPs flexible electrode in the absence and presence of different concentration of uric acid; supporting electrolyte: pH 6 PBS; scan rate $10 \mathrm{mVs}^{-1}$ (a); Calibration plots for HP $\left(5 \times 10^{-6}-10^{-4} \mathrm{M} U \mathrm{UA}\right)$, HP-

AuNPs $\left(5 \times 10^{-7}-10^{-4} \mathrm{M} \cup \mathrm{A}\right)$ and HP-AuNPs-PMB $\left(10^{-6}-10^{-4} \mathrm{M} \cup \mathrm{A}\right)$ electrode (b)

The electro-analytical parameters of screen-printed electrodes made on the stone paper substrate for uric acid detection are presented in Table 1.

Table 1. The electro-analytical parameters of HP, HP-AuNPs and HP-AuNPs-PMB electrodes for UA detection

\begin{tabular}{|c|c|c|c|}
\hline Electrode & $\begin{array}{c}\text { Sensitivity } \\
(\mathbf{m A} / \mathbf{M})\end{array}$ & $\begin{array}{c}\text { Linear range } \\
(\mathbf{M})\end{array}$ & $\begin{array}{c}\text { Detection limit } \\
(\mathbf{M})\end{array}$ \\
\hline HP & 1.23 & $5 \times 10^{-6}-10^{-4}$ & $1.6 \times 10^{-6}$ \\
\hline HP-AuNPs & 20.7 & $5 \times 10^{-7}-10^{-4}$ & $1.6 \times 10^{-7}$ \\
\hline $\begin{array}{c}\text { HP-AuNPs- } \\
\text { PMB }\end{array}$ & 11.7 & $10^{-6}-10^{-4}$ & $3.3 \times 10^{-7}$ \\
\hline
\end{tabular}

Here one can see that the limit of detection of HP-AuNPs electrode is considerably lower than that of HP (10 times) or HP-AuNPs-PMB electrode ( 2 times). In addition, it has the largest linear range for UA, from $5 \times 10^{-7}$ to $10^{-4}$ M. In Table 2 are shown the analytical performances of the new screenprinted electrodes made on the stone paper substrate for UA detection, in comparison with other types of electrodes. The low detection limit and the wide linear range highly recommend the HP-AuNPs electrode for practical applications. 
Table 2. Analytical performances of new screen-printed electrodes made on the stone paper substrate for UA detection, compared with other types of electrodes

\begin{tabular}{|c|c|c|c|c|c|}
\hline Electrode & Substrate & Technique & $\begin{array}{l}\text { LOD } \\
(\mu \mathrm{M})\end{array}$ & $\begin{array}{l}\text { Linear } \\
\text { range (M) }\end{array}$ & Ref. \\
\hline $\mathrm{HP}$ & Stone paper & $\mathrm{CV}$ & 1.6 & $5 \times 10^{-6}-10^{-4}$ & This work \\
\hline HP-AuNPs & Stone paper & $\mathrm{CV}$ & 0.16 & $5 \times 10^{-7}-10^{-4}$ & This work \\
\hline HP-AuNPs-PMB & Stone paper & $\mathrm{CV}$ & 0.33 & $10^{-6}-10^{-4}$ & This work \\
\hline PAMTA/PG & PG & DPV & 2.74 & $\begin{array}{l}5 \times 10^{-6}- \\
1.2 \times 10^{-3}\end{array}$ & [11] \\
\hline AuNPs/GO/Uricase & optical fiber & LSPR & 206 & $\begin{array}{c}1 \times 10^{-5}-8 \times 10^{-} \\
4\end{array}$ & [12] \\
\hline CNCo/GCE & GCE & DPV & 0.83 & $\begin{array}{l}2 \times 10^{-6}- \\
1.1 \times 10^{-4}\end{array}$ & [13] \\
\hline PEDOT/GCE & GCE & $\mathrm{CV}$ & 7 & $6 \times 10^{-6}-10^{-4}$ & [14] \\
\hline $\begin{array}{c}\alpha- \\
\text { Fe2O3/PAnNTs/GCE }\end{array}$ & GCE & DPV & 0.038 & $10^{-8}-5 \times 10^{-6}$ & [15] \\
\hline
\end{tabular}

PAMTA-2-amino-5-mercapto-1,3,4-thiadiazole; PG- pencil graphite, GO- graphene oxide, CNCo- N,Co-doped porous carbon, LSPR- localized surface plasmon resonance, PEDOTpoly(3,4-ethylenedioxythiophene, GCE- glassy carbon electrode, PAnNTs- polyaniline nanotube

\section{CONCLUSIONS}

In conclusions, flexible electrodes (HP) printed on stone paper and modified with AuNPs or AuNPs-PMB were employed for the electrochemical detection of uric acid, in standard laboratory solutions ( $\mathrm{pH} 6 \mathrm{PBS}$ ). The results were compared with those of bare electrode (HP). The best performances in terms of limit of detection $(0.16 \mu \mathrm{M})$ and linear range $\left(5 \times 10^{-7}-10^{-4} \mathrm{M}\right.$ uric acid $)$ were those of HP-AuNPs electrode.

\section{EXPERIMENTAL SECTION}

Chemical and reagents

All chemicals, including $\mathrm{KH}_{2} \mathrm{PO}_{4}, \mathrm{KCl}$, Potassium ferrocyanide $\mathrm{K}_{4}\left[\mathrm{Fe}(\mathrm{CN})_{6}\right]$ and $\mathrm{KCl}$ were purchased from Sigma-Aldrich. Uric acid was purchased from Alfa-Aesar. Double-distilled water was obtained with a Fistreem Cyclon water purification system and used to prepare all the solutions. Stone paper was purchase from MIQUELRIUS (Spain) and used as substrate for screen-printed electrode fabrication. 


\section{Apparatus}

Cyclic voltammograms (CV) were recorded with a potentiostat/ galvanostat Instrument (PGSTAT-302N, Metrohm-Autolab B.V., Netherlands). The experimental data were fitted using Nova 1.11 software.

A Hitachi SU8230 High Resolution Scanning Electron Microscope equipped with a cold field emission gun was used for obtain Scanning electron microscopy (SEM) images and energy-dispersive X-ray spectroscopy (EDS) analyses of stone paper electrodes.

Fabrication of flexible screen-printed electrodes on stone paper substrate

Stone paper, more durable than normal paper [21], was the flexible and water proof substrate for screen-printed electrode fabrication. The working electrode ( $4 \mathrm{~mm}$ diameter) and the counter were printed with carbon ink, while the reference electrode was printed with silver paste using a semiautomatic screen-printer (LC-TA-250 Model; NANOM MEMS SRL, Rasnov). The size of the obtained HP screen-printed electrode was: $3.4 \mathrm{x}$ $1.0 \times 0.05 \mathrm{~cm}(\mathrm{~L} \times \mathrm{W} \times \mathrm{H})$ (Figure 6).
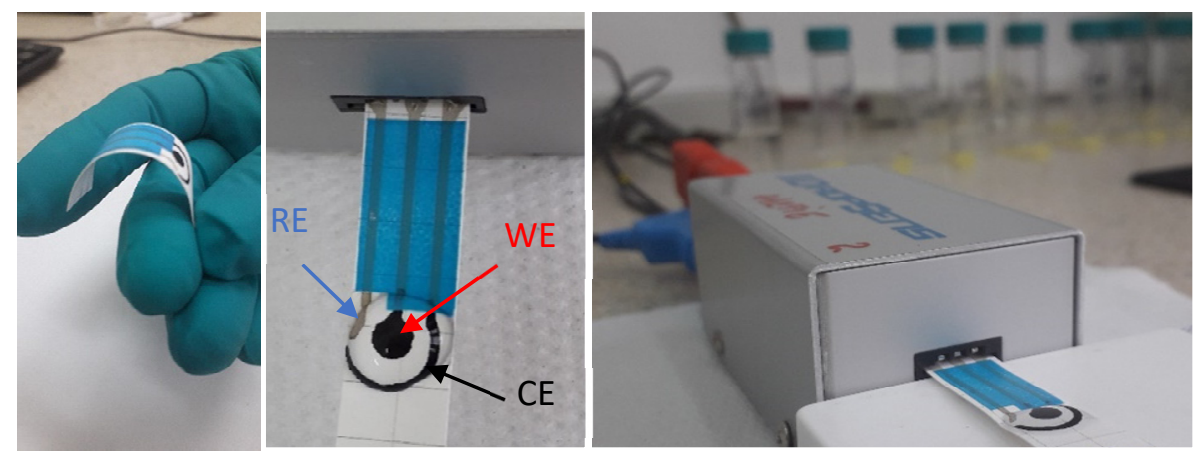

Figure 6. Flexible screen-printed electrodes on stone paper substrate (HP) (optical images)

In order to modify the working electrode with gold nanoparticles (AuNPs) the chronoamperometric method was employed. A drop of $60 \mu \mathrm{L}$ solution containing $1 \mathrm{mM} \mathrm{HAuCl}_{4}$ (in $0.5 \mathrm{M} \mathrm{H}_{2} \mathrm{SO}_{4}$ ) was put on top of HP electrode and a potential of $-0.2 \mathrm{~V}$ versus silver pseudo-reference electrode was applied, for 120 seconds. After AuNPs deposition, the electrode was cleaned with distilled water several times and was ready for further electrochemical investigation. The electrode was denoted HP-AuNPs. 
After AuNPs deposition, a Methylene Blue aqueous solution $\left(10^{-4} \mathrm{M}\right.$ in $\mathrm{pH} 7$ PBS) was added on top of HP-AuNPs electrode in order to form a polymeric film on its surface. The poly-methylene blue (PMB) layer was electro-deposited by sweeping the potential from -1 to $0.9 \mathrm{~V}$ at a scan rate of $50 \mathrm{mV} \cdot \mathrm{s}^{-1}$, for 30 cycles (Figure 7). The electrochemical signal of MB was observed at $\mathrm{E}_{\mathrm{pa}}=-0.3 \mathrm{~V}$.

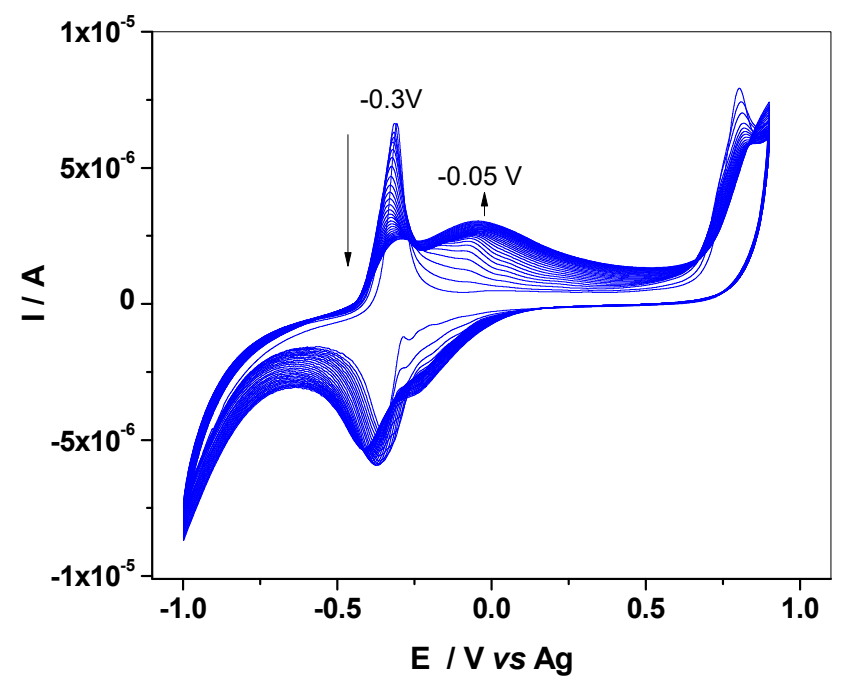

Figure 7. The electro-polymerization of Methylene Blue by cyclic voltammetry; $50 \mathrm{mV} \cdot \mathrm{s}^{-1}$ for 30 cycles

During the successive cycles the peak decreased in intensity and another peak grow-up at $-0.05 \mathrm{~V}$, corresponding to PMB. After polymerization, the modified electrode was thoroughly rinsed with double distilled water, airdried and denoted HP-AuNPs-PMB.

\section{ACKNOWLEDGMENTS}

This work was supported by a grant of Romanian Ministry of Research and Innovation, CNCS-UEFISCDI, project number PN-III-P4-ID-PCCF-2016-0006, within PNCDI III and by Nucleu Program contract no. PN 193501 02/2019. SEM/EDS measurements were partially supported through the infrastructure obtained in the Project: Research Center and Advanced Technologies for Alternative Energies CETATEA - POS-CCE 623/11.03.2014. Marin Gheorghe would like to thank UEFISCDI for funding (PN-III-P3-3.5-EUK-2017-02-0030, XploitAD). 
CODRUTA VARODI, FLORINA POGACEAN, MARIN GHEORGHE, LUCIAN BARBU-TUDORAN, STELA PRUNEANU

\section{REFERENCES}

1. G. Wurzner, J.C. Gerster, A. Chiolero, M. Maillard, C.L. Fallab-Stubi, H.R. Brunner, M. Burnier, J. Hypertens., 2001, 19, 1855-1860

2. J. Yu, S. Wang, L. Ge, S. Ge, Biosens. Bioelectron., 2011, 26, 3284-3289

3. J. Arora, S. Nandwani, M. Bhambi, C.S. Pundir, Anal. Chim. Acta, 2009, 647 (2), 195-201

4. T. Yamaguchi, K. Hasegawa, S. Kamino, K. Iyachi, H. Tominaga, Y. Fujita, Anal. Sci., 2007, 23, 223-226

5. R. Mundaca-Uribe, F. Bustos-Ramírez, C. Zaror-Zaror, M. Aranda-Bustos, J. Neira-Hinojosa, C. Pena- Farfal, Sens. Actuators B, 2014, 195, 58-62

6. A. Rodrigueza, R.M. Gomilab, G. Martorellb, A. Costa-Bauzaa, F. Grasesa, J. Chromatogr. B, 2017, 1067, 53-60

7. D. Remane, S. Grunwald, H. Hoeke, A. Mueller, S. Roeder, M. von Bergen, D. K. Wissenbach, J. Chromatogr. B, 2015, 998-999, 40-44

8. R. Ferin, M. L. Pavão, J. Baptista, Clin. L. Biochem., 2013, 46, 665-669

9. M.I. Khan, Q. Zhang, Y. Wang, S. Saud, W. Liu, S. Liu, H. Kong, C. Wang, A. Uzzaman, H. Xiao, L.-Y. Fan, C.-X. Cao, Sens. Actuators: B. Chem., 2019, 286, 9-15

10. N. Misra, V. Kumar, L. Borde, L. Varshney, Sensor Actuat. B-Chem., 2013, 178, 371-378

11. R.G. Krishnan, R.Rejithamol, B. Saraswathyamma, Microchem. J., 2020, 155, 104745

12. L. Singh, R. Singh, B. Zhang, S. Cheng, B.K. Kaushik, S. Kumar, Opt. Fiber Technol., 2019, 53, 102043

13. L. Liu, L. Liu,Y. Wang, Bang-Ce Ye, Talanta, 2019, 199, 478-484

14. M. Motshakeri, J. Travas-Sejdic, A.R.J. Phillips, P.A. Kilmartin, Electrochim. Acta, 2018, 265, 184-193

15. M.R. Mahmoudian, W.J. Basirun, M. Sookhakian, P.M. Woi, E. Zalnezhad, H. Hazarkhani, Y. Alias, Adv. Powder Technol., 2019, 30, 2, 384-392

16. V.R. Feig, H. Tran, Z. Bao, ACS Cent. Sci. 2018, 4, 337-348

17. X. Chen, J.H Ahn, J. Mater. Chem. B, 2020, 8, 1082-1092

18. G. Moro, F. Bottari, J. Van Loon, E. Du Bois, K. De Wael, L.M. Moretto, Biosens. Bioelectron. 2019, 146, 111758

19. C. Chu, P. Nel, AICCM Bull., 2019, 40, 37-49

20. Z.N. Nkunu, G.N. Kamau, J.G. Kithure, C.N. Muya, Int. J. Innov. Res. Sci. Eng. Technol. 2017, 4 (5), 53

21. J. He, M. Luo, L. Hu, Y. Zhou, S. Jiang, H. Song, R. Ye, J. Chen, L. Gao, J. Tang, J. Alloys Compd. 2014, 596, 73-78.6 